\title{
The Effects of Written Feedback On ESL Writers' Ability To Edit Word Choice Errors
}

Larysa Bobrova*

Miami University, USA

Corresponding Author: Larysa Bobrova, E-mail: bobrovl@miamioh.edu

\section{ARTICLE INFO}

Article history

Received: November 04, 2017

Accepted: December 20, 2017

Published: May 01, 2017

Volume: 7 Issue: 3

Advance access: March 2018

Conflicts of interest: None

Funding: None

\begin{abstract}
This study examines whether indirect written corrective feedback (CF) can enable 45 ESL writers with intermediate language proficiency to self-edit word choice errors classified as conceptual. Using a pre- and immediate post-test design, the study compares the effects of indirect CF under two conditions: errors are marked and coded without (1) and with metalinguistic explanation and (2) with two types of metalinguistic explanation: traditional and cognitive. Accuracy of word choice is measured in a new piece of writing. The results indicate that (1) CF with metalinguistic explanation is more useful than that without explanation (the control group) and (2) cognitive explanation (the cognitive group) appears to be significantly more effective than one drawn on the traditional account of language (the traditional group). The findings suggest that, when the $\mathrm{CF}$ attends to word choice errors as conceptual by addressing the mismatch between L2 forms and their conceptual content structured through cognitive frames and conceptual metaphors, ESL student writers are likely to make correct assumptions about syntagmatic connections of L2 words and correct more erroneous words in their L2 writing than when they are exposed to the feedback that approaches word choice errors as simply lexical and focuses on form-form mismatches.
\end{abstract}

Key words: Feedback, Word Choice Error, Metaphors, Cognitive Frame

\section{INTRODUCTION}

The intense debate about whether corrective feedback (CF) facilitates student accuracy in writing continues to stay on the research agenda in second language (L2) writing, even as researchers and educators have become more interested in issues surrounding the pedagogical techniques language instructors and L2 writers find more effective. Findings are mixed. Some studies on CF have compared the benefits of direct correction where corrections are edited into writing with indirect correction that utilizes either coded (when metalinguistic information about the specific type of error is provided), or uncoded (errors are underlined or circled), or marginal strategies, e.g. the number of errors in a given line is marked in the margin (Robb et al., 1986; Ferris \& Roberts, 2001; Ferris, 2002, 2006; Chandler, 2003; Ellis et al., 2006). Other studies have investigated the effect of direct $\mathrm{CF}$ alone and with written and/or oral metalinguistic explanation, the purpose of which is to help student writers understand the nature of an error and how to corrected it (e.g. Bitchener et al., 2005; Bitchener 2008; Bitchener \& Knoch, 2010; Sheen, 2007). While showing no consistency in their findings on immediate effects, these studies suggest that direct feedback with metalinguistic explanation leads to longterm improvement in student writers' accuracy.

The provision of metalinguistic explanation typically accompanies focused feedback defined as feedback target- ing one or a few linguistic error categories (Bitchener et al., 2005; Ellis et al., 2008; Bitchener \& Knoch, 2010; Sheen, 2007). Despite covering a broad range of CF types, the studies on focused feedback mostly center on the errors that Ferris (1999) labels as "treatable," e.g. the use of the English article system (Bitchener \& Knoch, 2010; Sheen, 2010), subject-verb agreement (Ferris et al., 2013), verb tense, and the use of prepositions in their non-idiosyncratic (non-metaphorical) meaning (Bitchener et al., 2005). Due to their discrete and rule-governed nature, instructors can direct learners to a particular set of rules to resolve treatable errors (Ferris, 1999, p. 6). In contrast to the "treatable" category, "untreatable" errors, such as word choice, idioms, metaphorical-used prepositions, and sentence structure (e.g. missing or unnecessary words and phrases) have been a much less attractive area for researchers interested in focused CF with metalinguistic explanation. The possible reason behind low interest (Ferris \& Roberts, 2001 as cited in Chaney, 1999) might be the language instructors' preference for direct correction for they believe that, being insufficient, the students' proficiency level disables them to self-correct untreatable errors (Ferris, 2006). Another reason might stem from the "idiosyncratic" and "idiomatic" nature of untreatable errors (Ferris, 1999, p. 6), which possibly makes them, to a certain extent, unmanageable for language instructors to articulate an effective 
metalinguistic explanation because, as Tyler (2008) notes, they mostly rely on the traditional - i.e. structuralist/descriptive/functionalist - approaches to language that have served the bases for most English pedagogical grammars to explain grammatical and lexical phenomena (p. 457). The problem with the traditional representations of language is the failure to capture linguistic motivation underpinning regularities and systematic connections in grammar and lexis. Given that, instructors are not equipped with adequate theoretical tools to allow them to explain why a particular word can combine with a particular group of words, and thus, to students' inquiries regarding erroneous words in their writing, instructors typically reply "that's just the way it is" (Littlemore \& Juchem-Grundmann, 2010, p. 3) rather than explaining "recurring patterns of meaning extension" and clearing up form-meaning relationships (Tyler, 2008, p. 459).

This current study aims to show that wrong word choice defined as untreatable errors can be effectively treated if instructors approach them as ones that stem from conceptual differences in the L2 and L1 or students' interlanguage. The wrong choice of the verb talk in "*... We always talk a story" (Note 1) uttered by an ESL writer suffices as a typical example of an untreatable word choice error classified as conceptual because it indicates the incongruity between language form and conceptual content in the L1 (Chinese) and the L2 (English) (Danesi, 2003, pp. 67, 77). For a detailed discussion of the error type, see Word Choice Errors as Conceptual. Contributing to research on the indirect $\mathrm{CF}$ on wrong word choice, the goals of this study are twofold. First, it will compare the effects of indirect CF (marked and coded errors) alone and with the metalinguistic explanation on the ESL writers' ability to edit wrong word errors. Second, the benefits of the metalinguistic explanation of erroneous words in ESL writing drawn from the traditional (dictionary) views of word meaning will be compared with those based on cognitive (encyclopedic) approaches to word meaning. The following section reviews some of the findings from studies that have sought to examine feedback strategies focused on word choice errors among other errors committed in ESL writing.

\section{THE EFFECTS OF FEEDBACK ON WORD CHOICE ERRORS}

The research in second language acquisition shows that inappropriate lexical choices (word choice errors) are the most frequent errors (Lennon, 1991; Webber, 1993; James, 1998) that are most likely to disrupt communication (Russo, 1997; Danesi \& Grieve, 2010) and, therefore, they are less tolerable by native speakers (Carter, 1998). Despite the gravity of mistaken word choice, to date there are only a few available studies (Ferris, 2006; Ferris \& Roberts, 2001; Ferris et al., 2013) that consider the effects of direct and indirect feedback treatments on wrong word errors (in addition to other untreatable and treatable errors) in L2 writing through quantitative and qualitative longitudinal approaches. Given the conflicting results these studies reported, the specific effects of treatments for word choice errors remain unclear. Word choice was among fifteen categories of treatable and untreatable errors that Ferris (2006) examined in regard to the responsiveness of 92 "Generation 1.5" student writers (U.S.-educated students who either were born or arrived in the U.S. at an early age) to instructors' feedback in the short and long term. The study's important finding comprises the fact that, though originally instructors agreed to provide indirect coded feedback on all fifteen types of errors, Ferris (2006) reported that the treatable/untreatable dichotomy affected the instructors' choice of intervention. Fifty nine percent of treatable errors received indirect feedback, while in more than 65 percent of the untreatable cases the instructors responded with direct intervention, i.e. a correct form was provided. From interviewing the instructors, Ferris (2006, p. 97) discovered that untreatable errors, including word choice, received direct corrections because, according to the instructors' beliefs, these errors are not amenable to students' self-correction despite the fact that the majority of them were "ear learners" (immigrant ESL students). The insignificant statistical difference between the ability of students to edit word choice in the short term and to avoid errors in the long term (Ferris, 2006, p. 91) suggests that direct feedback cannot ensure long-term improvement in accuracy despite high language proficiency of immigrant ESL student writers. This then poses the question whether direct corrections of word choice can be effective for other ESL populations, e.g. international students whose competence runs mostly from intermediate or low.

Both studies, Ferris and Roberts (2001) and Ferris et al. (2013), examined the efficacy of focused feedback targeting from three to four categories of errors, including wrong word errors. In their controlled experimental study with mostly longterm immigrants at a US university, Ferris and Roberts (2001) found that indirect feedback was more effective for treatable errors (verb errors, noun endings, articles) than untreatable errors, specifically sentence structure and word choice errors (p. 172). The group that received coded feedback, i.e. underlined errors with the identification of their types, was more successful in editing wrong word errors (63\%) than the group for which this type of error was only underlined (55\%) as well as the "no feedback" group (31\%). While the difference between the experimental groups' improvement was not statistically significant (Ferris \& Robert, 2001, p. 172), this finding is important because it leads to the following two observations. First, idiosyncratic untreatable wrong word errors are manageable for student writers to self-edit and do not necessarily require the direct correction that language instructors preferred in Ferris' study (2006, p. 96). Second, the strategies of coding and/or underlining produce a similar effect on the students' ability to self-edit choice word errors (Ferris \& Robert, 2001, p. 174) suggesting the need for a different and probably more explicit technique, for example, the combination of coding with a short metalinguistic explanation. As I show in Study Results, in the context of international students, this combined treatment is significantly more effective than coding alone for editing choice word errors stemming from the conceptual differences discussed in Word Choice Errors as Conceptual.

In contrast to Ferris' and Roberts' (2001) study, Ferris et al.'s (2013) multiple-case study suggests that ten first-year "Generation 1.5" college students in a basic writing course 
benefitted from focused explicit CF combined with revision sessions and discussions of errors. Ferris et al (2013) explain that the participants received their writing assignments with indirect feedback on the three or four most frequent error patterns, among which were word choice errors. Each error pattern was marked and coded, further explored, and explained in the revision session. It is notable that the strategy of "what 'sounds' right" mostly applied by "Generation 1.5 " writers was not always successful. Though the wrong-word pattern did not disappear completely from students' subsequent writing assignments, it became less frequent after the intervention (Ferris et al., 2013, p. 321). This suggests that focused indirect coded feedback combined with metalinguistic explanation in the form of retrospective interviews results in improvement in accuracy. Despite the success of the metalinguistic treatment reported in Ferris et al (2013), the researchers neither illustrate the explanation nor specify the theoretical approach employed to treat word choice errors, e.g. the traditional - i.e. structuralist/descriptive/functionalist - or cognitive linguistic approach. There is clearly a need for studies that explore whether different approaches to language and thus to word meaning (dictionary vs., encyclopedic) can change the effect of the metalinguistic $\mathrm{CF}$ on untreatable errors, word choice errors in particular. In this way, it might be possible to deepen our understanding of metalinguistic explanation aiding ESL student writers' self-editing. Informed by the insights from Ferris' (2006), Ferris et al.'s (2013), and Ferris' and Roberts' (2001) investigations, the present study compares the effectiveness of intervention drawn on two approaches to word meaning (dictionary - generated in traditional linguistics vs. encyclopedic - promoted in cognitive linguistics).

\section{The Effect of Feedback Informed by Cognitive Linguistics}

Findings from cognitive linguistics lending effective support to language instruction have been documented for teaching various aspects of the lexis-grammar continuum, specifically polysemous lexical units (Boers, 2000; Csábi, 2004; Lindstromberg \& Boers, 2005), figurative expressions (Boers, 2001; Boers, Demecheleer, \& Eyckmans, 2004; Boers \& Lindstromberg, 2008; Kövecses, 2001), figurative language in teaching English for Specific Purposes (Charteris-Black \& Ennis, 2001; Caballero Rodriguez, 2003), ESL writing (MacArthur, 2010), prepositions (Boers \& Demechelleer, 1998; Tyler et al., 2011; Tyler, 2012), the English article system (Huong, 2005; Verspoor, 2009 as cited in Tyler, 2012), and clause-level constructions (Kim, 2010 as cited in Tyler, 2012). However, little has been said about how cognitive linguistics can aid the metalinguistic $\mathrm{CF}$ on errors in these domains. To date, two studies (Abbuhl, 2005; Hama, 2005) have employed the cognitive linguistic account of English modal verbs (Talmy, 1988; Sweetser, 1990) to help law school students with an advanced level of language proficiency self-edit their writing. After being exposed to a 30-minute explicit explanation drawn on the cognitive linguistic view of English modals, the students who reported to have traditional instruction of English could appropriate- ly self-edit more English modals in their second drafts than before the instruction. Moreover, Hama (2005) reported an increase in the correct usage of modals in subsequent pieces of writing ( 30 pieces total) thereby attesting to the long-term effect of the explanation. In conjunction with the successful implementation of the cognitive linguistic approach to the instructional learning of grammar and lexis, Hama's (2005) and Abbuhl's (2005) preliminary results have shown some promise relating to the benefits that cognitive linguistics can offer to ESL writing scholarship and warrant further investigation of feedback techniques to respond to treatable and, especially, untreatable errors, including word choice errors, which is the focus of the present study.

\section{WORD CHOICE ERRORS AS CONCEPTUAL}

In the present study, the treatment of word choice errors adopts the encyclopedic model of linguistic meaning operationalized in cognitive semantics as a conceptual structure that, arising from human bodily experience, represents the networks of encyclopedic knowledge about culture, society (i.e. sociocultural interaction), and the physical world (i.e. interaction with the physical world) (Evans and Green, 2006, p.157-160). The encyclopedic knowledge prompted by lexical units involves different aspects of their conceptual structure (Sweetser, 1999) activated by cognitive frames (Fillmore, 1975, 1985, Fillmore \& Atkins, 1992) and conceptual metaphors (Lakoff \& Johnson, 1980). The former is assumed to monitor literal meanings, and the latter comes into play with intended metaphorical meanings. Some cognitive frames and conceptual metaphors available in the L1 can overlap with or diverge from those in English as being shaped by different cultures. To mention a few examples, emotions (e.g. anger, happiness, and love) are metaphoricalized differently in English and Chinese (Yu, 1995), Hungarian (Kövecses, 2005), Korean (Cho, 1994), Japanese (Matsuki, 1995). The conceptualization of time varies in English and Chinese (Chun, 2002), Kuuk Thaayorre - the Australian aboriginal language - (Boroditsky \& Gaby, 2010), Aymara - an Amerindian language spoken in western Bolivia, southeastern Peru, and northern Chile (Núñez \& Sweetser, 2006). English and Korean categorize spatial scenes by bringing to attention their different aspects (Bowerman \& Choi, 2003). The unawareness of divergences between L2 frames and metaphors and those in L1 cultures tend to result in word choice errors because ESL writers might rely on L1 cognitive frames or conceptual metaphors to make assumptions about how to collocate words in L2 discourse, as illustrated in example (1) in Conceptual Errors: The Violation of the Frame Potential of L2 Lexical Units. Word choice errors stemming from the negative transfer of frames and metaphors from the L1 or student's interlanguage to the L2 can be defined as conceptual because they involve cognitive transfer (Pavlenko, 1998) of "patterns of conceptualization (or ways of thinking)" acquired in the L1 and transferred to the L2 (Jarvis \& Pavlenko, 2008, p. 115). Given that conceptual errors are categorized into two types: the violation of the frame and metaphorical potential of L2 lexical units. 


\section{Conceptual Errors: The Violation of the Frame Potential of L2 Lexical Units}

Cognitive frames are viewed as "cognitive structures $[\ldots]$ knowledge of which is presupposed for the concepts encoded by the words" (Fillmore \& Atkins, 1992, p. 75). This means that cognitive frames, as "organized packages of knowledge" about reality and everyday social practices, are associated with linguistic forms (words and grammatical patterns) against which their meaning is understood and by which their grammatical behavior in sentences is sanctioned (Fillmore \& Baker, 2012, p. 314). Frames pinpoint the connection of everyday events (e.g. telling stories or talking with people), participants (e.g., interlocutors) and objects (e.g., stories) involved in them, and the literal meaning of words (e.g., we, stories, tell, talk) that describe them. In doing so, cognitive frames designate the number of participants required for an event, their nature, and the semantic roles they assume while precluding those participants whose nature does not meet the frame requirements (Fillmore \& Baker, 2012, p. 314 as cited in Brachman \& Schmolze, 1985). This dictatorship of frames, known as valence, is consequential for the collocational behavior of words when they make meaningful sentences. Valence controls the ways in which lexical items - verbs, nouns, adjectives, adverbs - may or may not be combined to make grammatical sentences by shaping syntactic slots into which words can be inserted. Being associated with a particular frame, a word assumes particular collocational requirements imposed by the frame. This means that if an English word is interpreted against a wrong frame, e.g., an L1 frame rather than the frame it authentically belongs to, this word becomes responsible for the erroneous choice of other words in the utterance. By way of illustration, consider the noun story that the student collocates with the verb talk in (1) *We always talk a story (Note 2). The noun story does not collocate with the verb talk because, in English, these two words activate two distinct frames whose composition is different in terms of their semantic roles. The noun story activates the frame of giving information while the verb talk activates the frame of information exchange. The frame of giving information implies the action of telling expressed by the verb tell in example (1) and two core (Note 3) semantic roles: speakers (we) and information (story). However, it precludes the explicit expression of other roles, e.g. the role of the listener. Relating to the frame of information exchange, the verb talk requires also two but different core roles: two interlocutors alternating the roles of a speaker and a listener while precluding other roles, e.g. information (story). In (1), the use of the verb talk with the noun story resulted in the conflict of the two frames because the frame of giving information precludes the role of the listener as a core role whereas the frame of information exchange precludes the role of information as shown in Table 1.

Interpreting the noun story against the wrong frame might originate from Chinese where the words story and talk share the same frame, i.e. information exchange, rather than being associated with two distinct frames as they are in English. Though the verbs talk and tell are translated into Chinese by two distinct verbs, 告诉 and 交谈, they are synonyms that can be used interchangeably and thus exhibit the same collocational constraints sanctioning the phrase talk a story meaning to discuss a story (Sharoff, 2006). Example 1 illustrates a word choice error classified as conceptual because the negative transfer of the frame effective in Chinese to English violates the frame potential of an English lexical unit.

\section{Conceptual Errors: The Violation of the Metaphors Potential of L2 Lexical Units}

Another source of conceptual errors might be conceptual metaphors in the cases of their variations across languages and cultures (Danesi, 2016; Kövecses, 2005, 2010). Conceptual metaphors as "understanding and experiencing one kind of thing in terms of another" (Lakoff \& Johnson, 1980, p. 5) allow us to understand, think, and write about abstract concepts in terms of the knowledge derived from the concrete experiences of our bodies in the sociocultural and physical world. This means that conceptual metaphorical organizes the domain of our knowledge about abstract concepts (the target domain) in terms of our knowledge about concrete concepts (the source domain) by singling out and projecting similar salient features from the source to the target domain (Lakoff \& Johnson, 1980). If the understanding of an abstract concept is motivated by the cognitive, social, and bodily experiences irrelevant to L2 culture, conceptual metaphorical might become a source of word choice errors, as happens in example (2):

(2) *As a pioneer who eliminate terrorists, those military bases actually do their responsibility but not show off their advanced weapons ....

The verb do indicates that the student associates the bodily experience of performing action (e.g. doing homework, cleaning) with the abstract concept of (Note 4) and thus violates the metaphorical potential of the English noun responsibility because its syntagmatic behavior is governed by the metaphors responsibilities are possessions/burdens (Lakoff et al., 1991, p. 206) sanctioning the verbs take, have, shoulder, bear rather do. Hence, the reliance on the metaphors irrelevant to English gives rise to the wrong assumptions about the syntagmatic connections of responsibility as shown in Table 2.

This conceptual error does not attest to negative conceptual transfer (Pavlenko, 1998) because, similar to English, Chinese conceptualizes responsibilities as possessions/ burdens collocating the noun responsibility with the verbs: 负 (take upon oneself), 承担 (undertake/shoulder), 逃避 (evade), 分担 (share), 免除 (exonerate) and the adjectives heavy and light (Sharoff, 2006). The use of do might attest to the principle - it sounds too similar to the L1, therefore it is wrong - that L2 learners sometimes follow (Ortega, 2009, p. 53), inhibiting L1 positive transfer. Example 2 illustrates a word choice error that can be classified as conceptual because the transfer of the metaphors effective in a student's interlanguage to English violates the metaphorical potential of an English lexical unit.

The explanation of conceptual errors violating the frame potential (examples 1) and metaphorical potential (example 
2) in light of the theory of cognitive frames (Fillmore, 1975) and the conceptual metaphors theory (Lakoff \& Johnson, 1980) allows for the capture of "recurrent organizing principles" found in language by revealing the systematic and non-arbitrary connections in the lexis (Tyler, 2012, p. 4), the awareness of which effectively facilitates self-editing of word choice errors in ESL writing as the results of the present study demonstrate.

\section{THE STUDY}

To contribute to the discussion of the CF effects highlighted in the reviewed studies and metalinguistic CF on word choice errors classified as conceptual, the present study seeks to answer the following research questions:

1. Are there differences in the student's ability to edit word choice errors across two feedback conditions (marked and coded errors alone and with metalinguistic explanation)?

2. Is there any difference in the effect of traditional (the dictionary model of meaning) and cognitive (the encyclopedic model of meaning) metalinguistic explanation on the student's ability to edit word choice errors?

\section{The Target Structure}

The focus of the study comprises word choice errors categorized as conceptual errors violating the frame potential (example 1) and metaphorical potential (example 2).

\section{Participants}

The study involved ESL students and instructors. The firstyear university ESL students were 45 native speakers of Chinese enrolled in ESL composition classes at an intermediate level. After eliminating students who were absent from either the pre-test or post-test phases of the study, the number of participants consisted of 38. They had studied English about 6-10 years before coming to the U.S. and resided in the U.S. less than a year. They received either at least a score of 65-79 on the Internet-based TOEFL test, or IELTS results of 5.5 or 6.0 , or an ELS score of 112, and were conditionally enrolled in a U.S. university. To matriculate at the university, they all were required to take a semester-long writing class for international students aimed to prepare them for the academic writing requirements of the university.

Four experienced instructors of ESL composition, two of whom were English native speakers, participated in the study. Their experience in teaching English as a second and foreign language ranged from 8 to more than 20 years at the university level. The educational background information collected from the instructors through the survey indicated that, first, they had completed courses in Linguistics (Phonetics, Generative Phonology, Semantics, Pragmatics, Corpus Linguistics), Pedagogy (Teaching Methods, Second Language Writing, Pedagogical Grammar) and SLA, earning $\mathrm{MA}$ and $\mathrm{PhD}$ degrees in Composition, TESOL, English/Second Language Writing, and Education Policy Studies with a focus on English; and, second, the instructors had been exposed neither to Cognitive Linguistics nor to its application in second language teaching and learning.

\section{Method \\ Design}

To answer the research questions, the study used a quasi-experimental design involving intact classes serving as two experimental groups - traditional metalinguistic CF $(N=13)$, cognitive metalinguistic $\mathrm{CF}(N=13)$ - and a control group $(N=12)$. All three groups completed a pre-test and an immediate post-test after the treatment. Each test included error correction tests and writing tasks. The schedule for the study is shown in Table 3. There was a gap of one week between the Writing Pre-test and Error Correction Pre-test needed for the elicitation of the traditional metalinguistic feedback from ESL instructors. The ESL instructors were asked to explain the wrong word errors marked in 30 sentences selected from the pre-test writing task to the researcher, if they agree that those words were misused. Their explanation was audio recorded, transcribed, and its content was analyzed in order to identify feedback strategies.

In Week 3, the students received the error correction pretest with the marked and coded errors collected from the writing tests the students completed in Week 1 . They were given as much time as needed to edit the errors. In Week 4, all three

Table 1. The violation of the frame potential activated by the English word story

\begin{tabular}{|c|c|c|c|c|}
\hline \multirow[t]{2}{*}{ Frames } & \multicolumn{3}{|c|}{ Core semantic roles } & \multirow[t]{2}{*}{ Linguistic elaboration } \\
\hline & Speakers (we) & Listeners (we) & Information (story) & \\
\hline Tell: giving information & we & - & a story & We always tell a story. \\
\hline $\begin{array}{l}\text { Talk: information } \\
\text { exchange }\end{array}$ & we & we & - & $\begin{array}{l}\text { *We always talk a } \\
\text { story. }\end{array}$ \\
\hline
\end{tabular}

Table 2. The violation of the metaphorical potential of responsibility in English

\begin{tabular}{llll}
\hline Language & Target domain & Source domain & Linguistic elaboration \\
\hline $\begin{array}{l}\text { Student's interlanguage } \\
\text { English }\end{array}$ & RESPONSIBILITIES & ACTION & $*$ do responsibility \\
& & POSSESSIONS/BURDENS & $\begin{array}{l}\text { take/have/shoulder/bear } \\
\text { responsibilities }\end{array}$ \\
\hline
\end{tabular}


Table 3. The schedule for the study

\begin{tabular}{llcc}
\hline Group & Traditional & Cognitive & Control \\
\hline Week 1 & Pre-test: a writing task & \\
Week 3 & Pre-test: an error correction test with marked and coded errors & \\
& & Treatment & Marked and coded \\
Week 4 & Marked and coded errors with & Marked and coded errors with & errors \\
& traditional metalinguistic CF & cognitive metalinguistic CF & \\
Week 5 & & Post-test: an error correction test & \\
\hline
\end{tabular}

groups received feedback on their word choice errors in the error correction post-test. For the control group, the errors were marked and coded; and, for the experimental groups, the feedback combined marking and coding errors with their metalinguistic explanation. The traditional group was given feedback elicited from the ESL instructors who relied on the dictionary model for meaning advocated within the traditional approach to language as the analysis shows in Traditional Metalinguistic CF. The cognitive group received feedback developed by the researcher drawing on the encyclopedic model for meaning advocated by cognitive linguistics. The time for the second editing was not limited. In Week 5, the students completed the new (second) piece of writing.

\section{Treatment: Focused Indirect Explicit CF}

This type of feedback is operationalized as the combination of marking and coding one type of errors (word choice errors) alone or with metalinguistic explanation (traditional and cognitive) given in written form. The explanation does not provide a correct form.

\section{Traditional Metalinguistic $C F$}

The metalinguistic explanation elicited from the ESL instructors is defined as traditional because the underlying assumption behind the reviewed explanations rests on the beliefs that word choice errors are of a lexical nature and present deviations from the form exhibited in the L2. These views are consistent with the dictionary model for meaning promoted in the traditional accounts of language. Given that the instructors applied form-focused explanations, this made linguistic elements salient to the students by directing their attention to their meanings or collocational behavior as in Laufer and Girsai (2008) and Laufer (2011). Regardless of the type of errors, the violation of (1) the frame or (2) metaphorical potential of words, the combination of two strategies was used in feedback: (1) the clarification of the dictionary meaning of a wrong word and (2) the provision of its collocation patterns, whose connections were not explained, or just one of them. For example, to address the misused word talk in example (3), which presents the violation of the frame potential, the instructors focused on its collocational patterns, pointing to the fact that talk is used with a prepositional phrase "about the subject" such as "life, college, money." As one of the instructors specified, "stories are not talked about, they are given directly. If you talk about the story, you wouldn't be sharing the story." Another instructor brought to attention a few incorrect collocations, saying that "there is no talk, speak or say a story." Also, one of the instructors gave a prompt in the form of a question: "What word would you use with the word "about"? - to encourage the student to think of a word with the required collocational behavior. I ensured that the traditional metalinguistic explanation incorporated the instructors' prompts shared in the interviews:

(3) *We always talk a story.

Explanation: talking about the story does not mean sharing the story. Talk is used with such words as about and the subject of a story, e.g. life, college, money. There is no talk, speak, say a story. What verb would you use?

To address the error stemming from the violation of the metaphorical potential in (4), the instructors relied mostly on the dictionary definition of the noun responsibility while attempting to draw attention to its metaphorization by noting that "responsibility cannot be physically produced."

(4) *As a pioneer who eliminate terrorists, those military bases actually do their responsibility but not show off their advanced weapons ....

Explanation: responsibility means a duty or being accountable for something. You cannot do it because responsibility is not an assignment or homework. What verb would you use?

\section{Cognitive Metalinguistic CF}

To edit the word choice errors violating the metaphorical or frame potential of English lexical units, the students received metalinguistic explanations developed by the researcher adopting the encyclopedic model of meaning generated in cognitive linguistics. Depending on the type of errors - the violation of the frame or metaphorical potential of words the explanation utilized the strategies based on the theory of either cognitive frames (Fillmore, 1975) or conceptual metaphors (Lakoff \& Johnson, 1980). Avoiding the metalanguage of cognitive linguistics that ESL students are not expected to know, the explanation in (5) attempts to (1) alert the students to the conflict between the frames that talk and story evoke, i.e. the frame of information exchange vs. the frame of giving information, (2) specifies the semantic roles each frame requires, i.e. the information exchange frame implies two interlocutors alternating in the roles of speaker and listener while giving the information frame requires the roles of the speakers and information; and (3) prompts the semantic role 
that agrees with the frame of story in order to help the students find a word with the syntagmatic connections that graft with those of story.

(5) *We always talk a story.

Explanation: talk requires the speaker and listener. The listener is not mentioned in the sentence. What verb would you use if you want the speaker (we) to share information (a story)?

To enable L2 student writers to correct word choice errors originating from metaphorical transfer, the metalinguistic feedback in (6) attempts to make the students aware of the metaphorical association between the abstract concept of RESPONSIBILITIES and the concrete physical concept of PosSESSIONS/BURDENS appealing to their experience with possessing objects.

(6) *As a pioneer who eliminate terrorists, those military bases actually do their responsibility but not show off their advanced weapons ....

Explanation: American speakers talk about responsibility the same way as they talk about objects that they possess or want to possess (e.g. a book, a car). What verb would you use if you want to say that you own something (e.g. a car or responsibility) or want to own something?

By noting that the metaphors belongs to American culture, the explanation attempts to sensitize students to the difference between the source domains in English as well as either in their L1 or interlanguage. The question intends to help students choose a verb that complies with the syntagmatic restrictions of the noun responsibility that emphasizes its association with possessions.

It should be reiterated that the explicitness of metalinguistic explanations was strictly controlled. Neither of the types of explanations (traditional or cognitive) provided correct forms. Second, the explanations differ in approaches to language, i.e. traditional linguistics vs. cognitive linguistics, and thus to word meaning, i.e. the dictionary vs. encyclopedic models respectively. Given the theoretic framework, the traditional explanation focuses on form-form relationships, treating word choice errors as lexical, and thus neglects the two distinct types of collocational violation: the frame and metaphorical potential of lexical units. Avoiding this failure, the cognitive explanation clarifies the conceptual mechanism underlying each kind of violation centering on the incongruous concept-form interactions that erroneous words exhibit, being approached as conceptual errors.

\section{Tests}

The study used two types of tests: (1) writing tests and (2) error correction tests.

Writing Tests

There were two writing assignments. The first writing assignment was used in the pre-test and consisted of inviting the students to make a claim about any concept representing American culture, and the other was used in the post-test, asking the students to make a claim about their improvement in English academic writing. These assignments were chosen for several reasons. First, they were not artificial as they were part of the students' course work in an academic writing program. Second, different topics intended to ensure multiple opportunities to utilize diverse vocabulary units with particular collocational patterns. The writing conditions were the same, i.e. outside writing tasks.

\section{Error Correction Tests}

For the pre- and post-tests, each group completed different error correction tests. Each test consisted of 10 sentences, each displaying one word choice error. The tests were piloted with native speakers of English until each sentence received 100\% agreement on the word choice errors. The participants were asked to correct a misused word in each sentence, disregarding grammar issues possibly displayed in the sentence. The targeted misused words were in red to ensure that participants focus on them. The word with which the misused word was collocated was in bold. For each of the tests, five sentences displayed the misused words caused by the violation of their frame potential and another five sentences included the misused words caused by the violation of metaphorical potential. Table 4 and 5 show samples of the pre- and post test items.

\section{Scoring and Analysis}

To examine the effects of the three types of treatment (marked and coded, marked and coded with traditional metalinguistic explanation, and marked and coded with cognitive metalinguistic explanation) on the student's ability to edit word choice errors, I obtained scores for each of the writing tasks and error correction tests administered for the pre-test and post-test.

The writing tests were coded for wrong word errors by the researcher. The word was coded as incorrectly chosen for the particular context when its collocational behavior in the similar context was not exhibited in the COCA (Davies, 2008-) or judged as incorrect by a native speaker. As in Ferris and Roberts (2001), the normalized error score for each individual essay was obtained using Biber's, Conrad's, and

Table 4. Error correction pre-test

Instruction: Read the sentences carefully paying special attention to the words in bold type. The words in red are wrong. Correct them.

*We always talk a story.

Table 5. Error correction post-test

Instruction: Read the sentences carefully paying special attention to the words in bold type. The words in red are wrong. Read the explanation and correct the words in red.

*We always talk a story.

Explanation: talk requires the speaker and listener. The listener is not mentioned in the sentence. What verb would you use if you want the speaker (we) to share information (a story)? 
Reppen's (1998) formula. Word choice errors were related to open class lexical items: nouns, verb, adjectives, and adverbs. The error counts were divided by the number of words (open class) in the text and then multiplied by a standard number representing the average number of words (open class) in the whole sample. In this case, the number was 466. I obtained open class word counts by processing each essay in the Online Word Counter program (Scott, 2007) (Note 5). To examine the reliability of the scoring of the writing tests, I adopted the procedure from Ellis et al. (2008). Five essays randomly selected from each group produced for the pre-test (15 essays total) were rescored one month after the test was initially scored. The correlation for the two sets of scores was.99.

In the error correction tests, one point was awarded for each successfully corrected error in 10 sentences. The maximum possible score for each test was 10 .

All scores were entered into SAS/STAT version 13.1. for computing descriptive and inferential statistics. The pre-test scores for the writing tests were analyzed by means of a oneway analysis of variance (ANOVA) to establish consistency across the three groups (traditional, cognitive, and control groups) followed by a mixed model ANOVA (three groups $\times$ two times) to investigate changes over time with planned contrast comparisons to test for differences between the group-specific mean scores from the pre- to post-tests. The scores for the error correction tests were computed by logistic regression analysis, utilizing group as the sole factor to establish consistency across the three groups at the pre-test phase. To investigate changes over time (the pre- to post-tests) and how this might differ among the three groups in respect to estimated proportions, a generalized estimating equation (GEE) model was used with planned contrast comparisons.

\section{STUDY RESULTS}

\section{Writing Test}

A one-way ANOVA revealed that there were no significant differences among the three groups' scores on the pre-test $(\mathrm{F}(2,35)=0.90, \mathrm{p}=0.4145)$. As Table 6 shows, all three groups decreased the number of wrong word errors from the pre-test to the post-test.

While the planned contrast comparisons of the group specific mean scores showed no significant change within the traditional group (mean change $=-1.75, \mathrm{SE}=1.11$, $\mathrm{t}(35)=-1.57, \mathrm{p}=0.1259)$ from the pre- to the post-test, there were significant reductions in the mean normalized error scores within the control group (mean change $=-3.165$, $\mathrm{SE}=1.16, \mathrm{t}(35)=-2.72, \mathrm{p}=0.0102)$ and the cognitive group (mean change $=-2.98, \mathrm{SE}=1.11, \mathrm{t}(35)=-2.66, \mathrm{p}=$ 0.0116 ). However, a mixed model ANOVA (three groups $\times$ two times) showed no significant interaction between group and time effects, essentially establishing that any change in the mean normalized error scores from the writing pre- to post-test was statistically consistent across the three groups $(F(2,35)=0.46, p=0.6354)$. This suggests that there is no strong statistical evidence that these three mean changes differ significantly by group.
Table 6. Descriptive statistics for the writing tests

\begin{tabular}{lccccc}
\hline Groups & N & \multicolumn{2}{c}{ Pre-test } & \multicolumn{2}{c}{ Post-test } \\
\cline { 2 - 6 } & & $\mathbf{M}$ & SD & M & SD \\
\hline $\begin{array}{l}\text { Traditional } \\
\text { metalinguistic CF }\end{array}$ & 13 & 6.23 & 2.69 & 4.47 & 3.56 \\
$\begin{array}{l}\text { Cognitive } \\
\text { metalinguistic CF }\end{array}$ & 13 & 6.29 & 3.29 & 3.31 & 2.38 \\
\begin{tabular}{l} 
Control \\
\hline
\end{tabular} & 12 & 7.95 & 4.64 & 4.78 & 3.75 \\
\hline
\end{tabular}

\section{Error Correction Test}

Similar to the writing pre-test, the three groups did not significantly differ on the error correction pre-test (Chi-square $=1.843, \mathrm{df}=2, \mathrm{p}=0.3978$ ). However, in contrast to the writing tests, the increase in the estimated proportions (EP) of correct error corrections displayed in Table 7 was significant in the traditional (Chi-square $=11.00, \mathrm{df}=1, \mathrm{p}=0.0009)$ and cognitive (Chi-square $=53.06, \mathrm{df}=1, \mathrm{p}<0.0001)$ groups, but insignificant in the control (Chi-square $=0.13$, df $=1, \mathrm{p}=$ $0.7233)$ group.

Three different pairwise treatment comparisons of preto-post-test changes in the estimated proportions of correct corrections showed highly significant improvement in the performance of the cognitive group relative to the control (Chi-sq $=10.09, \mathrm{df}=1, \mathrm{p}=0.0015)$ group and a significant difference relative to the traditional (Chi-sq $=5.11, \mathrm{df}=1, \mathrm{p}$ $=0.0238$ ) group. The improvement of the traditional group was marginally significant relative to the control $(\mathrm{Chi}-\mathrm{sq}=$ $4.08, \mathrm{df}=1, \mathrm{p}=0.0434$ ) group. The GEE model indicated a significant interaction (Chi-square $=10.80, \mathrm{df}=2, \mathrm{p}=$ 0.0045 ) between the treatment (traditional, cognitive, control) and time (pre- and post-tests).

\section{DISCUSSION}

The first research question concerned the relative effectiveness of CF across two conditions: marked and coded errors alone and those with metalinguistic explanation. In general, all three groups succeeded in correcting about one-third of word choice errors on the error correction pretest (Table 7). Aligning with the study of Ferris and Roberts (2001), this result suggests that ESL student writers are able to self-edit word choice errors after they are marked and coded, running counter to the language instructors' intuition as reported in Ferris (Ferris, 2006). However, as the results of the GEE model clearly indicate, the CF appeared significantly more effective when the errors are also explained (Chi-square $=10.80, \mathrm{df}=2, \mathrm{p}=0.0045)$, supporting the findings of Ferris et al. (2013). Its effectiveness can be explained by the Noticing (Schmidt, 1994) and Task-Induced Involvement Load (Lauder \& Hulijn, 2001) Hypotheses. When the student writers are assisted in noticing (Schmidt, 1994) that a particular adjective can modify only a particular set of nouns or a particular noun or adverb can collocate with a restricted set of verbs. The combinatorial properties and, especially, constraints of L2 words became salient, which is a crucial prerequisite for self-editing misused words in the L2. Aligning with the Task-Induced Involvement Load Hypothesis 
Table 7. Estimated proportions of correct error corrections

\begin{tabular}{lccccc}
\hline Groups & N & \multicolumn{2}{c}{ Pre-test } & \multicolumn{2}{c}{ Post-test } \\
\cline { 3 - 6 } & & EP & Std E & EP & Std E \\
\hline Traditional metalinguistic CF & 13 & 0.3154 & 0.04967 & 0.5000 & 0.03264 \\
Cognitive metalinguistic CF & 13 & 0.3923 & 0.03519 & 0.7615 & 0.02560 \\
Control & 12 & 0.3333 & 0.06905 & 0.3083 & 0.06062 \\
\hline
\end{tabular}

(Laufer \& Hulijn, 2001), metalinguistic clarification possibly helped both experimental groups recognize the need for a correct collocation and thus motivated them to search for a candidate with the appropriate syntagmatic connections, and, finally, to make a decision as to which connections a word in question should exhibit to fit the context.

The second research question asked whether there is any difference in the effect of $\mathrm{CF}$ with traditional and cognitive metalinguistic explanation on the student's ability to edit word choice errors. The difference in 10.09 between the estimated proportion score of the traditional (31\%) group and that of the cognitive (39\%) group is highly significant at $\mathrm{p}=$ $0.0015<0.05$, suggesting that the students found the cognitive feedback more beneficial than the traditional explanation on the error correction post-test. The finding can be explained by two reasons. First, approaching word choice errors as conceptual allows the cognitive CF to categorize them into two types: the violation of the frame and metaphorical potential of L2 words, and thus to propose treatment aiming at each type as a distinct case. Second, recognizing possible negative conceptual transfer (Pavlenko, 1998), the cognitive CF brings conceptual incongruity between the L1 or students' interlanguage and the L2 to students' attention. This way, the cognitive feedback sensitizes the ESL writers to false assumptions about the collocational behavior of L2 lexical units and possibly leads to the restructuring of the L2 conceptual system, which is a critical condition for improving lexical accuracy (Wolter, 2001, 2006; Jiang, 2002). In contrast to the cognitive CF, the traditional CF appeared less helpful probably because it treats erroneous words as simply a matter of lexical form (Peters, 2016; Laufer \& Waldman, 2011), failing to address each case of the mismatch between form and conceptual content (cognitive frames and conceptual metaphors) as distinct. As a consequence of this neglect, the traditional CF might fail effectively to facilitate the modification of L1 conceptual structures when they diverge from those in the L2, thus it might not sufficiently help the student writers to inhibit the L1 negative conceptual transfer when they collocate L2 words.

The results for the error correction tests were partially manifested in the writing post-test (a new piece of writing). The control and cognitive groups made significantly fewer word choice errors on the writing post-test than the traditional group (Table 6). The improvement in accuracy shown in the control group might be attributed to the avoidance of either new lexical units or those the usage of which the students were unsure. Another interpretation of the gain could be the influence of individual factors, e.g. analytic ability, motivation, an attitude to a writing assignment, that were beyond the scope of this study. The improvement of the cognitive group, which reduced the number of erroneous words by half on the writing post-test, may be explained by the possible enhancement of metalinguistic understanding that, as Ellis et al. (2008) claim, enables "conscious monitoring" of writing (p. 366). In the case of word choice errors, the metalinguistic understanding of the frame and metaphorical potential of English lexicon possibly enables the cognitive group not only to notice, but also consciously to monitor the syntagmatic connections of L2 words and thus probably inhibited the negative cognitive transfer from the L1 lexis. The decrease of the errors in the cognitive group indicates that the cognitive metalinguistic $\mathrm{CF}$ facilitated the procedural ability of the students appropriately to connect more English lexical units than those in the traditional group. Also, aligning with Littlemore (2009), Holme (2009), and Tyler (2008), this finding shows the importance of the knowledge about L2 conceptual structures (frames and metaphors) for building word-association networks in the L2 (Meara \& Wolter, 2004). Though the cognitive group outperformed the traditional and control groups on the writing post-test, the comparison of their gains shows no strong statistical evidence that lexical accuracy significantly differs by the various groups. As Hillocks (1986) and Chandler (2003) show in their studies, the increase in writing proficiency, specifically in lexical accuracy (Ferris et al., 2013), is a slow process in general, and it does not reveal immediate effects. Beside, it is important to note that the decrease in the transfer of $\mathrm{L} 1$ collocation connections to the $\mathrm{L} 2$ has been documented to be a complicated and continuous process (Nesselhauf, 2005; Laufer \& Waldman, 2011; Kathpalia \& Heah, 2011) as it involves the "fundamental restructuring" of L1 lexical/conceptual knowledge (Wolter, 2001; 2006, p. 744; Jiang, 2002). Even "Generation 1.5" students who were advanced speakers of English still were able to decrease but not ultimately eliminate word choice errors after multiple sessions of intervention held during the semester (Ferris et al., 2013). In contrast, the participants of the present study were ESL students with an intermediate level of language proficiency, and the experimental groups were exposed to a one-shot treatment. The fact that the cognitive group performed better on the writing posttest than the traditional and control groups and significantly outperformed them on the error correction test proved the effectiveness of the cognitive metalinguistic CF over the traditional CF. Finally, it should be noted that, despite the fact that the students had never been exposed to language instruction informed by cognitive linguistics, comprehension difficulties were not detected during the treatment.

\section{CONCLUSION}

In this article, the effort has been made to illustrate to ESL writing practitioners that, rather than being classified as untreatable, 
word choice errors can be viewed as treatable when they are approached as conceptual errors stemming from divergences between L1 and L2 conceptual structures, cognitive frames and conceptual metaphors specifically. Conceptual errors are classified into two types as those that violate the frame or metaphorical structure of L1 lexical units. In this way, inappropriately selected words become amenable for language instructors to develop CF conducive to students' self-editing the incongruity between the language form and conceptual content of the erroneous word in L2 writing and helps them consciously choose an L2 word with the appropriate syntagmatic connections. Embracing the findings on successful implementation of the theories of cognitive frames (Fillmore, 1975) and conceptual metaphors (Lakoff \& Johnson, 1980) for teaching grammar and lexis (see the discussion in The Effect of Feedback Informed by Cognitive Linguistics), I advocate for a metalinguistic CF that enhances the ESL student writers' awareness of the conceptual incongruity between the L1 and L2 conceptual systems as critical to improve lexical accuracy.

This study shows that the help given in the form of indirect $\mathrm{CF}$, i.e. correct forms were not provided, led to success of both experimental groups in correcting word choice errors. This means that, to self-edit erroneous words in their writing, student writers do not necessary require direct feedback that language instructors typically favor (Ferris, 2006) regardless of its downsides. Specifically, the provision of correct forms without explanation hinders metalinguistic understanding of not only linguistic forms, which is a decisive condition for their long-term acquisition (Ferris \& Roberts, 2001, p. 164), but also their syntagmatic links that, as Littlemore (2009) argues, is one of the aims of language teaching (p. 74). The present study shows that the provision of metalinguistic explanation of errors in addition to marking and coding them increases the performance of both experimental groups (Table 7). Moreover, the findings suggest that it is not only the degree of explicitness of CF, but also instructors' assumptions about the nature of language that play an important role in developing the explanation that would enable L2 writers to attend to corrections. The homogeneity in the student's ability to process and successfully utilize instructors' feedback appears higher in the condition of the CF with cognitive explanation than with the traditional one. The student writers found cognitive clarification more helpful because, approaching word choice errors as conceptual, it aimed to promote understanding of syntagmatic connections between lexical units activated by L 2 frames and metaphors. This understanding is a crucial factor in editing wrong word choices as they are prone to fossilize (Selinker, 1972; Laufer \& Waldman, 2011) due to the L1 negative conceptual transfer (Jarvise \& Pavlenko, 2008, p. 121). These findings can serve as a hypothesis that cognitive explanation helps students enhance over time metalinguistic understanding of organizational patterns in L2 lexis and develop the procedural ability to make correct word choices. To examine this issue, a longitudinal study is needed to carefully assess student progress in lexical accuracy in multiple new writing assignments after a series of treatments.

Finally, the study represents a springboard for further investigation of "how" questions that Ferris et al. (2013) define as "the most valuable to consider, going forward" in the
ESL writing scholarship on instructors' feedback (p. 324). The discussion of word choice errors as conceptual and the technique of the metalinguistic CF proposed in the present study will, hopefully, help writing instructors develop a clear understanding of the theoretical principles required for designing their own pedagogical materials in order to meet the particular needs of their students. The metalinguistic treatment drawn upon cognitive linguistics can be designed to address other treatable and untreatable errors made in the areas of grammar that cognitive linguists have insightfully analyzed in light of pedagogical techniques. The two pedagogical strategies proposed in the current study can be utilized in one-toone conferences and compared across two modalities, written and oral, to add to the effort of other L2 writing researchers (e.g. Sheen, 2007, 2010; Ferris et al., 2013) exploring their impact on the improvement in lexical accuracy.

\section{ACKNOWLEDGEMENTS}

I am indebted to my colleagues and students for their participation in the study. I am also grateful to James Lantolf and Kimberly Buescher for their constructive comments on the study. I am also thankful to Michael Naydan and the anonymous reviewers for helping me improve an earlier version of this article. This study was presented at the 2017 American Association for Applied Linguistics conference.

\section{END NOTES}

Note1. Asterisks mark sentences that contain errors.

Note 2. In addition to word choice errors, the data collected from the students' essays display various grammar issues that are disregarded as in (1) as they are not the target structures of the present study.

Note 3. It is important to clarify that core semantic roles are classified as obligatory (Fillmore \& Baker, 2012, p. 325) because their omission is consequential for the structured set of relationships that define how lexical units, like tell, story, and we, behave in a grammatically correct sentence. In contrast to the core semantic roles, the omission of peripheral semantic roles is not consequential for the structured set of relationships that defines how tell or story are understood and how they can be used. For example, the peripheral role of a listener elaborated by the prepositional phrase to the children does not influence the behavior of we or story in the sentence "We told a story to the children."

Note 4. Conceptual metaphors are marked in capital letters throughout the article.

Note 5. The number of the tokens "say" and "want" that the text tool included in the close class category were added to the counts of the open class category.

\section{REFERENCES}

Abbuhl, R. J. (2005). The effect of feedback and instruction on writing quality: Legal writing and advanced L2 learners. (Unpublished doctoral dissertation). Georgetown University, Washington DC. 
Biber, D., Conrad, S., \& Reppen, R. (1998). Corpus linguistics: Investigating language structure and use. Cambridge: Cambridge University Press.

Bitchener, J. (2008). Evidence in support of written corrective feedback. Journal of Second Language Writing, 17(2), 102-118.

Bitchener, J. \& Knoch, U. (2010). Raising the linguistic accuracy level of advanced L2 writers with written corrective feedback. Journal of Second Language Writing, 19, 207-217. doi: 10.1016/j.jslw.2010.10.002

Bitchener, J., Young, S., \& Cameron, D. (2005). The effect of different types of corrective feedback on ESL student writing. Journal of Second Language Writing, 14(3), 191-205.

Boers, F. (2000). Metaphors awareness and vocabulary retention. Applied Linguistics, 21(4), 553-571.

Boers, F. (2001). Remembering figurative idioms by hypothesizing about their origin. Prospect, 16(3), 34-43.

Boers, B. \& Demechelleer, M. (1998). A cognitive semantic approach to teaching prepositions. ELT Journal, 52(3), 197-204.

Boers, F., Demecheleer, M., \& Eyckmans, J. (2004). Etymological elaboration as a strategy for learning idioms. In P. Boggards \& B. Laufer (Eds.), Vocabulary in a second language: Selection, acquisition and testing (pp. 53-78). Amsterdam, Philadelphia: John Benjamins.

Boers, F., \& Lindstromberg, S. (2008). Structural elaboration by the sound (and feel) of it. In F. Boers \& S. Lindstromberg (Eds.), Cognitive linguistic approaches to teaching vocabulary and phraseology (pp. 329-353). Berlin, New York: De Gruyter.

Boroditsky, L. \& Gaby, A. (2010). Remembrance of times East: absolute spatial representations of time in an Australian aboriginal community. Psychological Science, 21, 1635-9.

Bowerman, M. \& Choi, S. (2003). Space under construction: language- specific spatial categorization in first language acquisition, in D. Gentner \& S. Goldin-Meadow (Eds.), Language in Mind: Advances in the Study of Language and Thought (pp. 387-428). Cambridge, MA: MIT Press.

Caballero Rodriguez, M. (2003). How to talk shop through metaphorical: bringing metaphors research to the ESP classroom. English for Specific Purposes, 22(2), 177194.

Carter, R. (1998). Vocabulary: Applied linguistics perspectives ( $2^{\text {nd }} \mathrm{ed}$.). London: Routledge.

Chandler, J. (2003). The efficacy of various kinds of error feedback for improvement in the accuracy and fluency of L2 student writing. Journal of Second Language Writing, 12(3), 267-296.

Charteris-Black, J., \& Ennis, T. (2001). A comparative study of metaphors in Spanish and English financial reporting. English for Specific Purposes, 20(3), 249-266.

Cho, S. (1994). Metaphors and cultural coherence: A comparative study of Korean and English metaphors. The Journal of Studies in Language, 10, 197-207.

Chun, L. (2002). A cognitive approach to Up/Down metaphors in English and Shang/Xia metaphors in Chinese.
In Altenberg, B. \& Granger, S. (Eds.), Lexis in contrast: Corpus-based approaches (pp. 151-174). Amsterdam/ Philadelphia: John Benjamin Publishing Company.

Csábi, S. (2004). A cognitive linguistic view of polysemy in English and its implications for teaching. In M. Achard \& S. Niemeier (Eds.), Cognitive linguistics, second language acquisition and foreign language teaching (pp. 233-256). Berlin, New York: De Gruyter.

Danesi, M. (2003). Second language teaching. A view from the right side of the brain. Dordrecht: Kluwer.

Danesi, M. (2016). Conceptual Fluency in Second Language Teaching: An Overview of Problems, Issues, Research Findings, and Pedagogy. International Journal of Applied Linguistics and English Literature, 5(1), 145-153.

Danesi, M. \& Grieve, C. (2010). Conceptual error theory and the teaching of Italian. Italica, 87, 1-20.

Davies, M. (2008-) The Corpus of Contemporary American English (COCA): 520 million words, 1990-present. Available online at http://corpus.byu.edu/coca/.

Ellis, R., Loewen, S., \& Erlam, R. (2006). Implicit and explicit corrective feedback and the acquisition of L2 grammar. Studies in Second Language Acquisition, 28, 339-368.

Ellis, R., Sheen, Y., Murakami, M., \& Takashima, H. (2008). The effects of focused and unfocused written corrective feedback in an English as a foreign language context. System, 36, 353-371.

Evans, V. \& Green, M. (2006). Cognitive linguistics: An introduction. Mahwah, NJ: Lawrence Elrbaum.

Ferris, D. R. (1999). The case for grammar correction in L2 writing classes. A response to Truscott (1996). Journal of Second Language Writing, 8, 1-10.

Ferris, D. R. (2002). Treatment of error in second language student writing. Ann Arbor: University of Michigan Press.

Ferris, D. R. (2006). Does error feedback help student writers? New evidence on the short- and long-term effects of written error correction. In K. Hyland \& F. Hyland (Ed.), Feedback in second language writing (pp. 81-104). Cambridge: Cambridge University Press.

Ferris, D. Liu, H., Sinha, \& A., Senna, M. (2013). Written corrective feedback for individual L2 writers. Journal of Second Language Writing, 22, 307-329.

Ferris, D. R., \& Roberts, B. (2001). Error feedback in L2 writing classes: How explicit does it need to be? Journal of Second Language Writing, 10, 161-184.

Fillmore, Ch. (1975). An Alternative to Checklist Theories of Meaning. Proceedings of the First Annual Meeting of the Berkeley Linguistics Society, 123-131.

Fillmore, Ch. (1985). Frames and the semantics of understanding. Quaderni di Semantica, 6, 222-54.

Fillmore, Ch., \& Atkins, B. T. (1992). Toward a frame-based lexicon: the semantics of RISK and its neighbors, in A. Lehrer \& E. F. Kittay (Eds.), Frames, Fields and Contrasts (pp. 75-102). Hillsdale, NJ: Lawrence Erlbaum.

Fillmore, C., \& Baker, C. (2012). A Frames Approach to Semantic Analysis. In Oxford Handbooks Online. Retrieved from http://www.oxfordhandbooks.com/ view/10.1093/oxfordhb/9780199544004.001.0001/ox- 
fordhb-9780199544004-e-013.

Hama, M. (2005). The effects of the minilesson on advanced learners' acquisition of English modals: A case study. (Unpublished manuscript). Georgetown University, Washington, DC.

Han, Z.-H. (2002). A study of the impact of recasts on tense consistency in L2 output. TESOL Quarterly, 36(4), 543-572.

Hillocks, G. (1986). Research on written composition: New directions for teaching. Urbana, IL: ERIC Clearinghouse on Reading and Communication Skills.

Holme, R. (2009). Cognitive Linguistics and Language Teaching. Basingstoke: Palgrave Macmillan.

Huong, N. T. (2005). Vietnamese learners mastering English articles. (Unpublished doctoral dissertation). University of Groningen, Groningen, Netherlands.

James, C. (1998). Errors in language learning and use. White Plains, NY: Addison-Wesley Longman.

Jarvis, S., \& Pavlenko, A. (2008). Crosslinguistic influence in language and cognition. Routledge.

Jiang, N. (2002). Form-meaning mapping in vocabulary acquisition in a second language. Studies in Second Language Acquisition, 24, 617-37.

Kathpalia, S., \& Heah, L. (2011). Metaphorical competence in ESL student writing. RELC Journal, 42(3), 273-290.

Kövecses, Z. (2001). A cognitive linguistic view of learning idioms in an EFL context. In M. Pütz, S. Niemeier, \& R. Dirven (Eds.), Applied cognitive linguistics II: Language pedagogy (pp. 87-115). Berlin, New York: De Gruyter.

Kövecses, Z. (2005). Metaphors in culture: Universality and variation. New York: Cambridge University Press.

Kovecses, Z. (2010). Metaphors: A practical introduction. Oxford University Press.

Lakoff, G., Espenson, J., \& Schwartz, A. (1991). Master Metaphors List. (Draft $2^{\text {nd }}$ Edition.) Berkeley. CA.: Cognitive Linguistics Group, University of California at Berkeley.

Lakoff, G., \& Johnson, M. (1980). Metaphors we live by. Chicago: Chicago University Press.

Laufer, B. and Hulstijn, J. (2001). Incidental vocabulary acquisition in a second language: The construct of task-induced involvement. Applied Linguistics, 22, 1-26.

Laufer, B., \& Waldman, T. (2011). Verb-noun collocations in second language writing: corpus analysis of learners' English. Language Learning, 61, 647-72.

Lennon, P. (1991). Error and the very advanced learner. International Review of Applied Linguistics, 29, 31-44.

Lindstromberg, S., \& Boers, F. (2005). Means of mass memorization of multi-word expressions. Part one: The power of sound patterns. Humanising Language Teaching, 7(1).

Littlemore, J. (2009). Applying cognitive linguistics to second language learning and teaching. Basingstoke: Palgrave Macmillan.

Littlemore, J., \& Juchem-Grundmann, C. (2010). Introduction to the interplay between cognitive linguistics and second language learning and teaching. AILA Review, 23(1), 1-6.
MacArthur, F. (2010). Metaphorical competence in EFL: Where are we and where should we be going? A view from the language classroom. AILA Review, 23(1), 155-173.

Matsuki, K. (1995). Metaphors of anger in Japanese. In Taylor, J. R. \& MacLaury, R. (Eds.), Language in the cognitive construal of the world (pp. 137-151) Berlin: Mouton de Gruyter.

Meara, P. M., \& Wolter, B. (2004). V_Links: Beyond vocabulary depth. Angles on the English speaking world, 4, 85-96.

Nesselhauf, N. (2005). Collocations in a learner corpus. Amsterdam: Benjamins.

Núñez, R. E., \& Sweetser, E. (2006). With the future behind them: Convergent evidence from Aymara language and gesture in the crosslinguistic comparison of spatial construals of time. Cognitive science, 30(3), 401-450.

Ortega, L. (2014). Understanding second language acquisition. Routledge.

Peters, E. (2016). The learning burden of collocations: The role of interlexical and intralexical factors. Language Teaching Research, 20(1), 113-138.

Pavlenko, A. (1998). SLA and acculturation: Conceptual transfer in L2 learners' narratives. In Annual AAAL Conference, Seattle, WA., March.

Robb, T., Ross, \& S., Shortreed, I. (1986). Salience of feedback on error and its effect on EFL writing quality. TESOL Quarterly, 20, 83-93.

Russo, G. A. (1997). A conceptual fluency framework for the teaching of Italian as a second language. (Unpublished doctoral dissertation), Toronto, University of Toronto.

Scott. (2007-2017). Online Word Counter. Retrieved April 17, 2017, fromhttp://www.textfixer.com/tools/online-word-counter.php\#newText2

Selinker, L. (1972). Interlanguage. International Review of Applied Linguistics in Language Teaching, 10, 209-231.

Sharoff, S. (2006). Creating general-purpose corpora using automated search engine queries. In Marco Baroni and Silvia Bernardini, editors, WaCk y! Working papers on the Web as Corpus. Gedit, Bologna.

Sheen, Y. (2007). The effect of focused written corrective feedback and language aptitude on ESL learners' acquisition of articles. TESOL Quarterly, 41, 255-283.

Sheen, Y. (2008). Recasts, language anxiety, modified output and L2 learning. Language Learning, 58, 835-874.

Sheen, Y. (2010). Differential effects of oral and written corrective feedback in the ESL classroom. Studies in Second Language Acquisition, 32, 203-234.

Schmidt, R. (1994). Deconstructing consciousness in search of useful definitions for applied linguistics. AILA Review, 11, 11-26.

Sweetser, Eve (1990) From Etymology to Pragmatics: Metaphors and Cultural Aspects of Semantic Structure. Cambridge: Cambridge University Press.

Talmy, L. (1988), Force Dynamics in Language and Cognition. Cognitive Science, 12: 49-100.

Tyler, A. (2008). Cognitive linguistics and second language instruction. Handbook of cognitive linguistics and second language acquisition, 456-488. 
Tyler, A. (2012). Cognitive linguistics and second language learning: theoretical basics and experimental evidence. New York: Routledge.

Tyler, A., Mueller, C. M., \& Ho, V. (2010). Applying cognitive linguistics to instructed to L2 learning: The English modals. AILA Review, 23, 30-49.

Tyler, A., Mueller, Ch., \& Ho, V. (2011). Applying cognitive linguistics to learning the semantics of English to, for and at: An experimental investigation. Vigo International Journal of Applied Linguistics, 8, 181-205.

Webber, P. (1993). Writing medical articles: a discussion of common errors made by L2 authors and some par- ticular features of discourse. UNESCO-ALSED LSP Newsletter, 15(2), 38-49.

Wolter, B. (2001). Comparing the L1 and L2 mental lexicon: A depth of individual word knowledge model. Studies in Second Language Acquisition, 23, 49-69.

Wolter, B. (2006). Lexical network structures and L2 vocabulary acquisition: The role of L1 lexical/conceptual knowledge. Applied Linguistics, 27, 741-747.

Yu, N. (1995). Metaphors expressions of anger and happiness in English and Chinese. Metaphors and symbol, 10(2), 59-92. 